\title{
Cardioprotective effect of melatonin-standardized ethanol extract of Ulva lactuca $L$ against acute myocardial infarction in rats induced by isoproterenol
}

\author{
Wahyu Widyaningsi $i^{1,2}$, Suwidjiyo Pramono ${ }^{3}$, Sitarina Widyarini ${ }^{4}$ and Dan \\ Sugiyanto ${ }^{5 *}$ \\ ${ }^{1}$ Faculty of Pharmacy, Gadjah Mada University, Yogyakarta 55281 Indonesia, ${ }^{2}$ Faculty of Pharmacy, Ahmad Dahlan \\ University, Yogyakarta Faculty of Pharmacy Ahmad Dahlan University, Yogyakarta, ${ }^{3}$ Laboratory of Phytochemistry, Faculty of \\ Pharmacy, ${ }^{4}$ Department of Patology, Faculty of Veterinary Medicine, Gadjah Mada University, ${ }^{5}$ Laboratory of Pharmacology \\ and Toxicology, Faculty of Pharmacy, Gadjah Mada University, Yogyakarta, Indonesia
}

*For correspondence: Email: widyaningsihwahyu@yahoo.com, dahlansugiyanto@yahoo.com

\begin{abstract}
Purpose: To investigate the cardioprotective effect of standardized melatonin ethanol extract of Ulva lactuca (smEEUL) against acute myocardial infarction induced by isoproterenol (ISO).

Methods: Male Wistar rats were divided into 6 groups of 6 rats each. Group A was control group given carboxymethylcellulose (CMC Na) while Group B was given ISO $85 \mathrm{mg} / \mathrm{kg} \mathrm{BW}$, subcutaneously. Groups $C, D$ and $E$ were given ISO plus smEEUL 250, 500 and $750 \mathrm{mg} / \mathrm{kg}$ orally, respectively. Group $F$ was given melatonin $10 \mathrm{mg} / \mathrm{kg}$. Both smEEUL and melatonin were administered for 28 days. ISO was injected twice, i.e., on days 29 and 30. At the end of the study, electrocardiogram (ECG) was recorded, and blood samples collected for myocardial necrosis enzyme assay. Macroscopic features of left ventricle of the heart were also examined using triphenyl tetrazolium chloride (TTC) staining

Results: ISO-treated group demonstrated a significant $(p<0.05)$ elevation in the level of creatine kinase (CK), lactate dehydrogenase (LDH) and aspartate aminotransferase (AST), with increase of 64.01, 65.66 and $99.40 \%$, respectively, compared with control group. ECG pattern from ISO also showed ST segment elevation. The groups given smEEUL reduced significantly the level of CK, LDH and ST segment elevation $(p<0.05)$. The highest dose showed a reduction $(p<0.05$ of 62.52 and $77.70 \%$ in the levels of CK and LDH, respectively, compared with ISO treated group. Macroscopic examination y using TTC staining supported the above results.

Conclusion: The results show that administration of smEEUL produces cardioprotective effect by restoring ST segment elevation, and reducing both the area of myocardial infarction and myocardial necrosis enzyme level.
\end{abstract}

Keywords: Cardioprotective, Ulva lactuca L, Isoproterenol, Melatonin, Myocardial necrosis and infarction, ST segment

Tropical Journal of Pharmaceutical Research is indexed by Science Citation Index (SciSearch), Scopus, International Pharmaceutical Abstract, Chemical Abstracts, Embase, Index Copernicus, EBSCO, African Index Medicus, JournalSeek, Journal Citation Reports/Science Edition, Directory of Open Access Journals (DOAJ), African Journal Online, Bioline International, Open-J-Gate and Pharmacy Abstracts

\section{INTRODUCTION}

Cardiovascular diseases remain a problem in Indonesia, one of which is acute myocardial infarction (AMI) [1]. AMl can be triggered by certain chemical compound resulting in the damage of myocardium cells [2]. In animal model, AMI may also induced by chemical agent. Isoproterenol is a nonselective $\beta$-adrenergic agonist for the induction of myocardial infarction in rats $[3,4]$, which can modulate cellular and 
functional responses in the heart by its reactive oxygen species [5].

Marine organisms are potential sources of highly bioactive secondary metabolites that are important in the development of new pharmaceutical agents [6]. Ulva sp is an algae which are numerous in coastal intertidal habitats worldwide [7]. Some studies have identified the melatonin on algae $[8,9]$. Melatonin also has been reported as the main compound of $U$. lactuca [9]. Pape and Luning, (2006) showed that $U$. lactuca contain melatonin approximately 12 $\mathrm{pg} / \mathrm{g}$ (fresh weight). Antioxidant activities and cardioprotective effect of melatonin have been reported in previous studies [10-12]. Administration of melatonin with the dose of 10 $\mathrm{mg} / \mathrm{kg} /$ day for 7 days in Sprague Dawley male rats has shown cardioprotective effect [13].

Compounds of natural origin can play important roles in prevention and treatment of various diseases. The main compound of $U$. lactuca (melatonin) has been reported to have antioxidant and cardioprotective effect. Therefore, in this study, melatonin standardized in the ethanol extract of $U$. lactuca (smEEUL) was used to investigate the cardioprotective effect against AMI induced by isoproterenol in Wistar rat.

\section{EXPERIMENTAL}

\section{Chemicals}

Isoproterenol hydrochloride and melatonin were purchased from Sigma Aldrich Co. St Louis. MO., USA. All other biochemical and chemical reagents used were of analytical grade.

\section{Collection and identification of plant materials}

Ulva lactuca $\mathrm{L}$ were collected at low tide in the afternoon in January 2015 from Drini Beach, Yogyakarta, Indonesia. Plant species was authenticated by Sujadmiko from Systematical Plant Laboratory, Faculty of Biology, Gadjah Mada University. A voucher specimen (no. 0626/S.Tb/l/2015) was deposited in the herbarium of Faculty of Pharmacy, Ahmad Dahlan University Yogyakarta, Indonesia

\section{Plant extraction}

Plant extraction was performed as previously described [14]. Briefly, algaes were washed with water, dried and were grinded to make powder. The powder was extracted with $96 \%$ ethanol by maceration method. Ethanol extract then was evaporated with a vacuum rotary evaporator at 4 ${ }^{\circ} \mathrm{C}$. The extract was filtered and dried at high vacuum and then stored in the refrigerator.

\section{Identification and determination of melatonin in ethanol extract of $U$. lactuca $L$}

Identification of melatonin was performed by thin layer chromatography (TLC) method [15]. TLC elution was carried out on Silica F254 eluted with a mobile phase of n-butanol-acetic acid-water (12: $3: 5)$ with melatonin as standard and then observed under UV light at $254 \mathrm{~nm}$. Determination of melatonin content was carried out using TLC densitometry and quantitated using the calibration curve of melatonin (0-2.0 $\mathrm{mg} / \mathrm{ml}$ ).

\section{Treatment of animals}

Male albino Wistar rats aged 7 - 8 weeks were used in this study. The animals were housed in air conditioned room and were kept in standard laboratory condition, which included a 12-h lightdark cycle and temperature $(25 \pm 2){ }^{\circ} \mathrm{C}$. The rats were fed with standard pellet diet AD-2 (Comfeed Industries Ltd) and water ad libitum. All procedures related with animal experiments were approved by the Animal Ethical Committee of Integrated Laboratory of Research and Testing (LPPT), Gadjah Mada University (no. 205/KECLPPT/XII/2014). Equipment including handling and sacrificing of the animals were in accordance with the Guide for the Care and Use of Laboratory Animals of US National Institutes of Health [16].

\section{Experimental design}

The procedure used followed that described previously [17]. The animals were randomly divided into 6 groups of 6 rats. Group A was control group and received carboxymethylcellulose (CMC-Na). Group B was given isoproterenol $85 \mathrm{mg} / \mathrm{kg} \mathrm{BW}$ - (ISO). Groups C, D, and $E$ were given ISO plus smEEUL 250, 500 and $750 \mathrm{mg} / \mathrm{kg} \mathrm{BW}$, respectively. Group F was given melatonin $10 \mathrm{mg} / \mathrm{kg} \mathrm{BW}$. Both smEEUL and melatonin were orally administrated for 28 days. ISO was injected subcutaneously twice, at days 29 and 30. At the end of the study (day 31), all the animals were anesthetized, electrocardiogram was recorded, and blood samples were collected from the infraorbital sinus for cardiac necrosis enzyme determination. Macroscopic features from left ventricle of the heart were also examined by using TTC staining to determine the area of myocardial infarction. 


\section{Electrocardiographic studies}

Rats were anesthetized with intraperitoneal injection of pentobarbital sodium (50 mg/kg BW). Needle electrodes were inserted under the skin (lead II position) and then ECG was recorded using animal electrocardiograph Nihon Kohden [2]. Changes in P-wave, QRS Complex and ST segment were determined from electrocardiogram result [17].

\section{Triphenyl tetrazolium chloride (TTC) staining}

Myocardial infarction staining was done as mentioned by Lie et al [17]. In brief, the heart was transversely cut across the left ventricle, and sections of 2 to $3 \mathrm{~mm}$ thick were incubated in 2 $\%$ TTC solution prepared in phosphate buffer $(\mathrm{pH}$ 7.4) for $60 \mathrm{~min}$ at $37^{\circ} \mathrm{C}$, following which they were fixed with $10 \%$ formalin. The slices subsequently were photographed using a digital camera, and the \% infarction was analyzed using the computerized Image J $(1.40 \mathrm{~g}$ Wayne Rasband National Institutes of Health, USA).

\section{Biochemical analysis of cardiac necrosis enzyme marker}

Animals were anesthetized (intraperitoneal injection of pentobarbital sodium $50 \mathrm{mg} / \mathrm{kg} \mathrm{BW}$ ), and blood was collected via infraorbital sinus. Plasma was separated by centrifugation $5000 \mathrm{xg}$ at $4{ }^{\circ} \mathrm{C}$ for $15 \mathrm{~min}$ and then kept at $-80^{\circ} \mathrm{C}$ for enzyme analysis. The markers of cardiac necrosis, such as creatine kinase (CK), lactate dehyrogenase (LDH) aspartate aminotransferase (AST) and alanine aminotransferase (ALT) in the plasma were then determined by commercial diagnostic kits (Biovision, Milpitas, CA 95035 USA and DiaSys, Holzheim, Germany).

\section{Statistical analysis}

Electrocardiogram results (duration of basal amplitude of $\mathrm{P}$ wave, QRS complex, STsegment), the area of myocardial infarction and the level of cardiac necrosis enzyme were expressed as mean \pm SEM and were analysed by one-way ANOVA followed by Dunnett's test for multiple comparison using SPSS version 16.0 for Windows. The results were considered significant at $p<0.05$.

\section{RESULTS}

\section{Presence of melatonin in smEEUL}

The identification of smEEUL by TLC densitometer method showed the presence of melatonin with retardation factor (Rf) 0.78 co- chromatographed with melatonin standard. The content of melatonin in smEEUL is $0.52 \pm 0.04 \%$ (0.52 mg melatonin/100 mg EEUL).

\section{Effect of smEEUL on electrocardiogram parameters}

Figure 1 shows the effect of smEEUL administration on the electrocardiogram parameter. Isoproterenol administration of 85 $\mathrm{mg} / \mathrm{kg}$ BW for 2 consecutive days led to acute myocardial infarction. ISO group demonstrated a decrease $(p<0.05)$ of the P wave and the QRS complex and elevation in the ST segment. However administration of various dose of smEEUL restored electrocardiogram parameter, such as, an increased in the $P$ wave and the QRS complex and a decreased ST segment compared with ISO $(p<0.10)$.

\section{Effect of smEEUL on the area of myocardial infarction}

It can be seen in Figure 2, by using TTC staining that the ISO-induced group showed a large infarct area (white to yellow colour area), while the control group demonstrated a red colour area. ISO-induced group showed a significant ( $p$ $<0.05$ ) increase of the myocardial infarction area (100\%), compared with the control-group. Administration of smEEUL at doses of 250, 500 and $750 \mathrm{mg} / \mathrm{kg}$ BW reduced $(p<0.05)$ the myocardial infarction area state as shown by $48.55 \%, 81.82 \%$, and $57.43 \%$, respectively compared with ISO treated group. The highest reduction of the area infarction can be found in the group treated with smEEUL $500 \mathrm{mg} / \mathrm{kg} \mathrm{BW}$.

\section{Effect of smEEUL on the level of myocardial necrosis enzyme markers}

As shown in Figure 3 , ISO treated group demonstrated a significant $(p<0.05)$ elevation in the level of creatine kinase (CK), laktat dehydrogenase (LDH) and aspartate aminotransferase (AST); an increase of $64.01 \%$, $65.66 \%$ and $99.40 \%$ respectively compared with the control group. Treatment with smEEUL 250, 500, $750 \mathrm{mg} / \mathrm{kg} \mathrm{BW}$ and melatonin 10 $\mathrm{mg} / \mathrm{kg} \mathrm{BW}$ reduce the level of CK by $26.48 \%$, $41.21 \%, 62.52 \%$ and $61.54 \%$, respectively, compared with ISO group. Compared with ISO treated group, the level of LDH was significantly $(p<0.05)$ reduced by $24.07 \%, 64.28 \%, 77.70$ $\%$ and $59.34 \%$ in group treated with smEEUL $250,500,750 \mathrm{mg} / \mathrm{kg} \mathrm{BW}$ and melatonin 10 $\mathrm{mg} / \mathrm{kg} \mathrm{BW}$, respectively. 


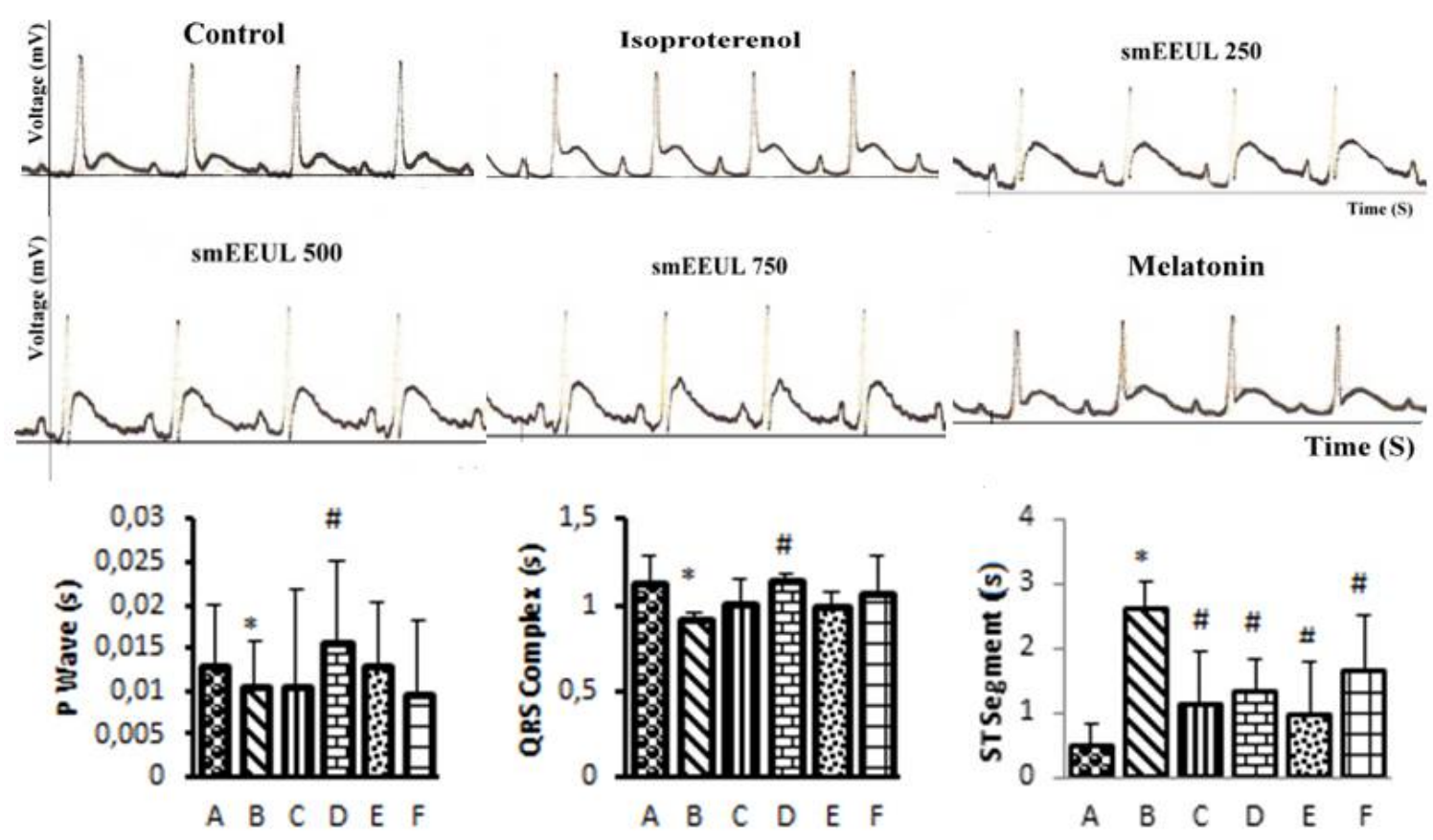

Figure 1: Effect of smEEUL on electrocardiogram parameters. $P$ wave, QRS complex and ST segment are expressed as mean \pm SEM. ${ }^{*} p<0.05$ compared with control; and ${ }^{*} p<0.05$ compared with ISO. $A=$ control group; $B$ = ISO group; $C=$ smEEUL 250 group; $D=$ smEEUL 500 group; $E=$ smEEUL 750 group and $F=$ melatonin $10 \mathrm{mg} / \mathrm{kg}$
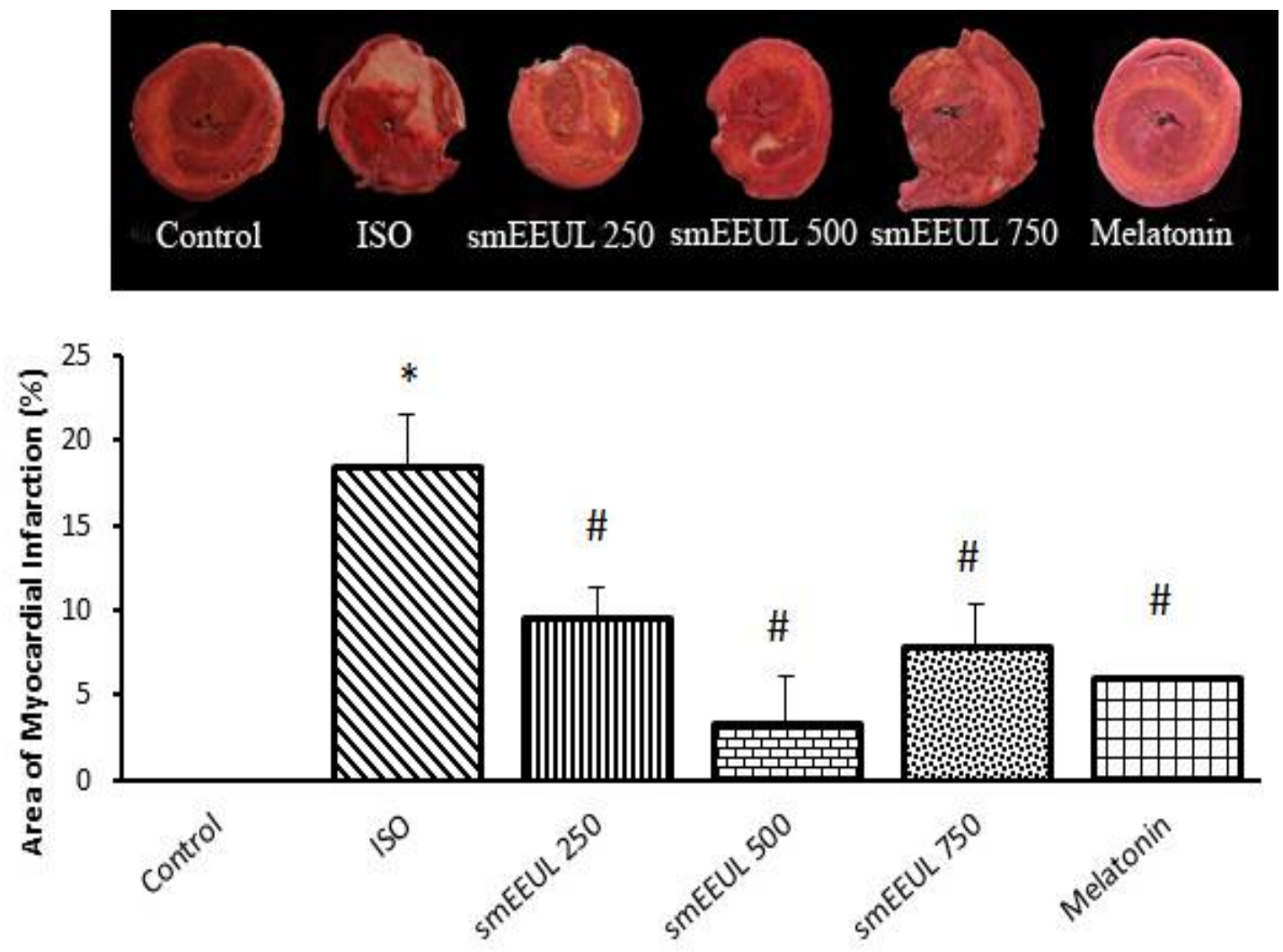

Figure 2: Area of myocardial infarction in the control and experimental animals. Normal myocardium was stained red, while pale white or yellow areas indicate infarct areas. Values are expressed asa mean \pm SEM $(n=6) ; p<$ 0.05 compared with control; ${ }^{*} p<0.05$ compared with ISO 

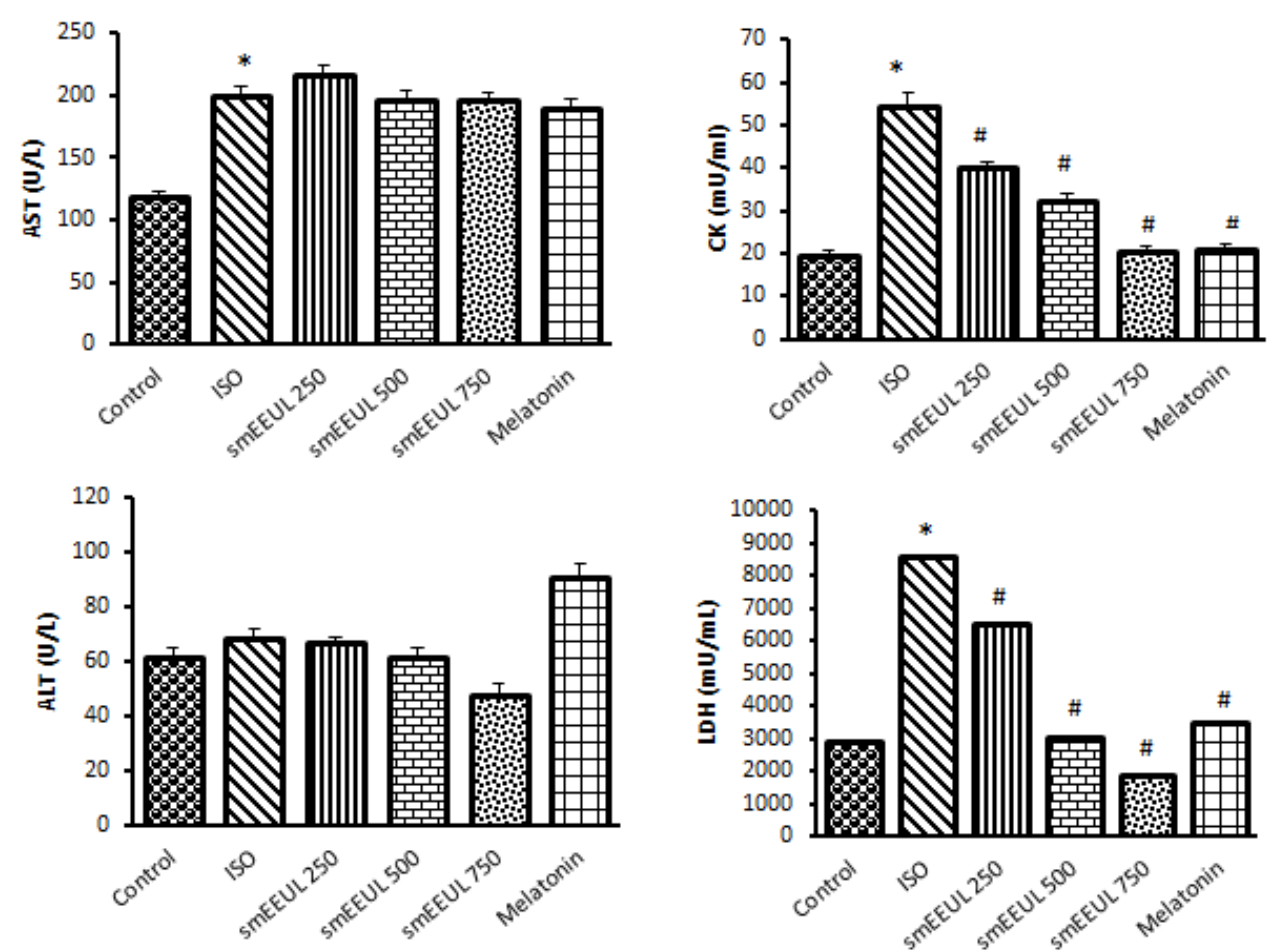

Figure 3: Effect of smEEUL on various cardiac necrosis enzyme marker. (All value are expressed as mean \pm SEM for $\mathrm{n}=6$. ${ }^{*} p<0.05$ compared with control; and ${ }^{\#} p<0.05$ compared with ISO)

\section{DISCUSSION}

Results of this study showed that ISO administration at $85 \mathrm{mg} / \mathrm{kg}$ for 2 consecutive days in male Wistar rat led to acute myocardial infarction. The main criteria generally used for the definite diagnosis of $\mathrm{Ml}$ is evolving pattern of electrocardiograph (ECG)-abnormalities. ISO administration lowered $P$ wave and QRS complex significantly and increased elevation in the ST segment. It has been reported in previous study that administration of ISO $85 \mathrm{mg} / \mathrm{kg}$ in two consecutive days in male SD rat increases the segment ST, QT interval and lower $P$ wave, RR interval and QRS complex [17]. Several studies also mentioned that elevation and depression of the ST-segment are typical in the AMI model in rats induced by ISO $[17,18]$. The change in ECG parameter is due to the changes in potential membrane in the area of infarction [17]. In this study various doses of smEEUL normalized ECG by increasing $P$ wave and QRS complex and decreasing ST segment. It thus seems that the melatonin content of EEUL can modify potential membrane in the area of infarction. However, the mechanism is not clear. Previous study reported that ST-segment elevation resulted in the loss of cell membrane function which reflects the potential difference in the boundary between ischemic and non-ischemic zones [19].

Reactive oxygen species (ROS) are formed in the myocardium due to ISO administration.
Mechanism of ISO-induced AMI involves causing impaired balance between the formation of free radicals and antioxidative defense system, cardiac dysfunction, increased lipid peroxidation and altered enzyme activity which affects the heart muscle [4]. Myocardial infarction increased activities of these marker enzymes (CK, LDH, AST and ALT) in the plasma and this indicates cellular damage and loss of functional permeability of the cell membrane [20]. Administration of smEEUL decreased the level of these enzyme markers of myocardial necrosis (CK and LDH, $p<0.05$ ). This indicates the protective action of smEEUL in preventing myocardial cell and membrane permeability damage by ISO.

Result in this study also demonstrated that smEEUL contains melatonin $0.52 \mathrm{mg}$ in $100 \mathrm{mg}$ EEUL. Therefore, smEEUL 250, 500 and 750 $\mathrm{mg} / \mathrm{kg}$ BW contains 1.3, 2.6 and $3.9 \mathrm{mg}$ melatonin respectively. The content of melatonin in this study is lower than mentioned in previous study. However, these above doses still have cardioprotective effect as shown from our study. Patel et al [] reported that administration of pure melatonin $10 \mathrm{mg} / \mathrm{kg} \quad \mathrm{BW}$ for 7 days has cardioprotective effects via its ability to restore ST segment elevation, and reduce myocardial necrosis enzyme marker [13].

Previous studies have shown an increase in infarct area due to isoproterenol as indicated with 
white to yellow colour by using TTC staining $[2,21]$. In this study, the level of the enzyme marker of myocardial necrosis (LDH) supported TTC staining results. It has been reported that the area of infarction show loss of membrane integrity that occurs because of the release of lactate dehydrogenase [21,22]. Administration of smEEUL not only significantly decreased the myocardial infarct area by TTC staining but also decreased the level of LDH.

Melatonin is not the only content of $U$. lactuca [23]. Previous research by Abirami et al and ElBaky proved that $U$. lactuca have active chemical compound, such as chlorophyll, carotenoids, vitamin C, polyphenols and polysaccaharides sulfate which have a role as an antioxidant $[24,25]$. Thus, in this study, the cardioprotective effect of smEEUL is not only as a result of melatonin, but also possibly by combining effects of melatonin and various compounds mentioned above such as chlorophyll, carotenoids, vitamin $\mathrm{C}$, polyphenols and polysaccaharides sulfate.

\section{CONCLUSION}

Oral administration of smEEUL for 28 days exhibits cardioprotective effect in rats by restoring ST segment elevation, as well as reducing the area of myocardial infarction and myocardial necrosis enzyme level. smEEUL has a potential to be developed to a cardiopreventive agent for the treatment of myocardial infarction in human.

\section{DECLARATIONS}

\section{Acknowledgement}

The authors extend their appreciation to KEMENRISTEK DIKTI Republik Indonesia for financial support for the work via a PhD grant.

\section{Conflict of Interest}

No conflict of interest associated with this work.

\section{Contribution of Authors}

The authors declare that this work was done by the authors named in this article and all liabilities pertaining to claims relating to the content of this article will be borne by them.

\section{REFERENCES}

1. WHO. WHO | Cardiovascular diseases (CVDs) [Internet]. WHO. 2011 [cited 2015 Dec 23]. Available from: http://www.who.int/entity/cardiovascular_diseases/en/ind ex.html

2. Li H, Xie Y-H, Yang $Q$, Wang S-W, Zhang B-L, Wang J$B$, Cao $W, B i$ L-L, Sun J-Y, Miao $S$, et al. Cardioprotective effect of Paeonol and Danshensu combination on isoproterenol-induced myocardial injury in rats. PloS One. 2012; 7(11): e48872.

3. Grimm $D$, Elsner $D$, Schunkert $H$, Pfeifer $M$, Griese $D$, Bruckschlegel G, Muders F, Riegger G, Kromer E. Development of heart failure following isoproterenol administration in the rat: role of the renin-angiotensin system. Cardiovasc Res. 1998; 37(1): 91-100.

4. Rathore $N$, John $S$, Kale M, Bhatnagar D. Lipid peroxidation and antioxidant enzymes in isoproterenol induced oxidative stress in rat tissues. Pharmacol Res Off J Ital Pharmacol Soc. 1998; 38(4): 297-303.

5. Zhang G-X, Kimura S, Nishiyama A, Shokoji $T$, Rahman $M$, Yao L, Nagai $Y$, Fujisawa $Y$, Miyatake A, Abe $Y$. Cardiac oxidative stress in acute and chronic isoproterenol-infused rats. Cardiovasc Res. 2005; 65(1): 230-238.

6. El Gamal AA. Biological importance of marine algae. Saudi Pharm J SPJ. 2010; 18(1): 1-25.

7. Einav $R$, Israel A. Seaweeds on the Abrasion Platforms of the Intertidal Zone of Eastern Mediterranean Shores. In: Seckbach DJ, editor. Algae and Cyanobacteria in Extreme Environments [Internet]. Springer Netherlands; 2007 [cited 2015 Dec 21\}. p. 193-207. (Cellular Origin, Life in Extreme Habitats and Astrobiology). Available from: http: //link.springer.com/chapter/10.1007/978-14020-6112-7_10

8. Hardeland R, Poeggeler B. Non-vertebrate melatonin. $J$ Pineal Res. 2003; 34(4): 233-241.

9. Paredes SD, Korkmaz A, Manchester LC, Tan D-X, Reiter RJ. Phytomelatonin: a review. J Exp Bot. 2009; 60(1): 57-69.

10. Reiter R, Tang L, Garcia JJ, Muñoz-Hoyos $A$. Pharmacological actions of melatonin in oxygen radical pathophysiology. Life Sci. 1997; 60(25): 2255-2271.

11. Yang Q, Gao B, Ye Z, Wang J, Bruce IC, Xia Q. Opening the calcium-activated potassium channel participates in the cardioprotective effect of puerarin. Eur J Pharmacol. 2007; 574(2-3): 179-184.

12. Tal O, Haim A, Harel O, Gerchman Y. Melatonin as an antioxidant and its semi-lunar rhythm in green macroalga Ulva sp. J Exp Bot. 2011; 62(6): 1903-1910.

13. Patel V, Upaganlawar A, Zalawadia R, Balaraman $R$. Cardioprotective effect of melatonin against isoproterenol induced myocardial infarction in rats: $A$ biochemical, electrocardiographic and histoarchitectural evaluation. Eur J Pharmacol. 2010; 644 (1-3): 160-168.

14. Puteriragil $P$, Widyaningsih $W$. The effect of ethanol extract of ulva lactuca I on sgpt-sgot activity in rat [Internet]. [cited 2015 Dec 22]. Available from: http://mot.farmasi.ugm.ac.id/artikel-191-the-effect-ofethanol-extract-of-ulva-lactuca-l-on-sgptsgot-activity-inrat.html 
15. Prabowo. Pemanfaatan Phytomelatonin Ganggang Hijau (Spirogyra sp.) sebagai Cancer Activity Inhibitor dari Induksi Logam Berat. 2009

16. Guide for the Care and Use of Laboratory Animals, 8th edition. National Academies Press - Guide-for-the-Careand-use-of-laboratory-animals.pdf [Internet]. US National Research Council of National Institute of Health; [cited 2016 May 28]. Available from: https: //grants.nih.gov/grants/olaw/Guide-for-the-Care-anduse-of-laboratory-animals.pdf

17. Upaganlawar A, Vaibhav $P$, Balaraman R. Tomato lycopene attenuates myocardial infarction induced by isoproterenol: Electrocardiographic, biochemical and anti-apoptotic study. Asian Pac J Trop Biomed. 2012; 2(5): 345-51.

18. Peacock DB, Roe MT, Chen AY, Diercks WF, Kirk JD, Pollack CV, et al. Prolonged emergency department stays of non-ST-segment-elevation myocardial infarction patients are associated with worse adherence to the American College of Cardiology/American Heart Association guidelines for management and increased adverse events. Ann Emerg Med. 2007; 50(5): 489-196.

19. Bahit MC, Murphy SA, Gibson CM, Cannon CP. Critical pathway for acute ST-segment elevation myocardial infarction: estimating its potential impact in the TIMI 9 Registry. Crit Pathw Cardiol. 2002; 1(2): 107-112.
20. Farvin KH, Anandan R, Kumar SHS, Shiny KS, Sankar $T V$, Thankappan TK. Effect of squalene on tissue defense system in isoproterenol-induced myocardial infarction in rats. Pharmacol Res. 2004; 50(3): 231-6.

21. Csonka DJ, Kupai K, Csont T, Szucs G, Bester C, Esterhuyse $A J$, et al. Dietary red palm oil supplementation reduces myocardial infarct size in an isolated perfused rat heart model. Lipids Health Dis. 2010; 9: 64.

22. Panda S. Butanolic fraction of Moringa oleifera Lam. (Moringaceae) attenuates isoprotrenol-induced cardiac necrosis and oxidative stress in rats: an EPR study. EXCLI J. 2015; 14: 64-74.

23. Pape C, Lüning K. Quantification of melatonin in phototrophic organisms. J Pineal Res. 2006; 41(2): 157165.

24. Abirami RG, Kowsalya S. Nutrient and Nutraceutical Potentials of Seaweed Biomass Ulva lactuca and Kappaphycus alvarezii. J Agric Sci Technol. 2011; 5(1) 107-115.

25. El-Baky HHA, El-Baz FK, El-Baroty GS. Evaluation of marine alga Ulva lactuca $L$ as a source of natural preservative ingredient [Internet]. 2008 [cited 2014 Sep 22]. Available from: http://eurekamag.com/research/ 031/322/031322802.php 